\title{
Fabrication and Characterization of Regenerated Cellulose Films Using Different Ionic Liquids
}

\author{
Jin-Hui Pang, ${ }^{1}$ Xin Liu, ${ }^{1}$ Miao Wu, ${ }^{1}$ Yu-Ying Wu, ${ }^{2}$ Xue-Ming Zhang, ${ }^{1,2}$ and Run-Cang Sun ${ }^{2,3}$ \\ ${ }^{1}$ MOE Key Laboratory of Wooden Material Science and Application, Beijing Forestry University, Beijing 100083, China \\ ${ }^{2}$ Institute of Biomass Chemistry and Technology, Beijing Forestry University, Beijing 100083, China \\ ${ }^{3}$ State Key Laboratory of Pulp and Paper Engineering, South China University of Technology, Guangzhou, China
}

Correspondence should be addressed to Yu-Ying Wu; wuyuying-1980@163.com and Xue-Ming Zhang; xm_zhang@bjfu.edu.cn

Received 21 April 2014; Accepted 7 May 2014; Published 9 June 2014

Academic Editor: Shao-Wen Cao

Copyright (C) 2014 Jin-Hui Pang et al. This is an open access article distributed under the Creative Commons Attribution License, which permits unrestricted use, distribution, and reproduction in any medium, provided the original work is properly cited.

\begin{abstract}
The demand for substitution of fossil-based materials by renewable bio-based materials is increasing with the fossil resources reduction and its negative impacts on the environment. In this study, environmentally friendly regenerated cellulose films were successfully prepared using 1-allyl-3-methylimidazolium chloride (AmimCl), 1-butyl-3-methylimidazolium chloride (BmimCl), 1ethyl-3-methylimidazolium chloride (EmimCl), and 1-ethyl-3-methylimidazolium acetate (EmimAc) as solvents, respectively. The results of morphology from scanning electron microscopy (SEM) and atomic force microscopy (AFM) showed that all the cellulose films possessed smooth, highly uniform, and dense surface. The solid-state cross-polarization/magic angle spinning $(\mathrm{CP} / \mathrm{MAS}){ }^{13} \mathrm{C}$ NMR spectra and X-ray diffraction (XRD) corroborated that the transition from cellulose I to II had occurred after preparation. Moreover, it was shown that the ionic liquid EmimAc possessed much stronger dissolubility for cellulose as compared with other ionic liquids and the cellulose film regenerated from EmimCl exhibited the most excellent tensile strength (119 Mpa). The notable properties of regenerated cellulose films are promising for applications in transparent biodegradable packaging and agricultural purpose as a substitute for PP and PE.
\end{abstract}

\section{Introduction}

With the development of modern society and industry, there is growing demand for development of renewable and biodegradable materials as substitutes for petroleum-derived synthetic polymers [1]. Cellulose is the most abundant natural polymer in nature and it will become one of the most promising polymeric resources, which is renewable, biodegradable, and biocompatible $[2,3]$. However, chemical processing of cellulose is extremely difficult in general because it is neither meltable nor soluble in water or common solvents due to its partially crystalline structure and close chain packing via numerous inter- and intramolecular hydrogen bonds $[4,5]$.

Over the past decades, several cellulose solvent systems have been available for dissolving cellulose, such as viscose process $\left(\mathrm{CS}_{2}\right)[6,7], \mathrm{LiCl} / \mathrm{N}, \mathrm{N}$-dimethylacetamide (DMAc) [8], DMSO/paraformaldehyde (PF) [9], and some aqueous solutions of metal complexes [10]. However, these conventional cellulose solvent systems have disadvantages, such as limited dissolving capability, toxicity, high cost, solvents recovery, uncontrollable side reaction, and instability during cellulose processing and/or derivatization. The recently developed Lyocell process [11], which uses $\mathrm{N}$ methylmorpholine $\mathrm{N}$-oxide (NMMO) to dissolve cellulose directly, also has some disadvantages including the formation of byproducts, the degradation of cellulose, and high cost [12]. In recent years, Zhang et al. [13, 14] have developed a green and efficient method for dissolution of cellulose in $\mathrm{NaOH} /$ urea aqueous solution, in which the cellulose can be rapidly dissolved as precooled to $-12^{\circ} \mathrm{C}$ within $2 \mathrm{~min}$. However, the dissolution process is limited in terms of cellulose concentration and degree polymerization (DP). More recently, ionic liquids (ILs) have attracted much attention due to their high electrochemical and thermal stability, nonflammability, and tunable solubility properties [15]. Ionic liquids are often fluid at room temperature and consist entirely of ionic species and represent a new class of solvents 
with high polarity. Since no toxic or explosive gases are formed due to their low vapor pressure, ionic liquids are considered as "green solvents." Moreover, ionic liquids exhibited outstanding dissolving capability for cellulose [16], which will broaden the comprehensive utilization for cellulose. It has been shown that the ability to dissolve cellulose is not an inherent property of this broad class of compounds [17]. Among the vast number of ILs reported so far, only a minority dissolve cellulose. In order to compare the dissolubility and processability of different ionic liquids on cellulose, four ILs including 1-allyl-3-methylimidazolium chloride ( $\mathrm{AmimCl})$, 1-ethyl-3-methylimidazolium chloride (EmimCl), 1-butyl3-methylimidazolium chloride $(\mathrm{BmimCl})$, and 1-ethyl-3methylimidazolium acetate (EmimAc) were chosen as solvents to dissolve cellulose and elaborate regenerated cellulose films. The morphology, chemical structure, and mechanical properties of cellulose films were investigated to evaluate the desirability of their applications in the packaging and functional materials fields.

\section{Materials and Methods}

2.1. Materials. Cotton linter, supplied by Silver Hawk Fiber Corporation (Shandong province, China), was used as cellulose sample with the degree of polymerization (DP) 920 . The degree of polymerization was measured by TAPPI test method using cupriethylenediamine (CED) as a solvent and a capillary viscometer, to give an indication of the average degree of polymerization of the cellulose materials. The viscosities determined as centipoises $(\mathrm{cP})$ were converted to degree of polymerization (DP) based on the following formula:

$$
\mathrm{DP}^{0.905}=0.75 \times[954 \times \log (X)-325],
$$

where $X=$ TAPPI viscosity in cP.

The cellulose sample used was dried in vacuum at $105^{\circ} \mathrm{C}$ for $24 \mathrm{~h}$ before using. The ILs 1-ethyl-3-methylimidazolium acetate (EmimAc), 1-allyl-3-methylimidazolium chloride (AmimCl), 1-ethyl-3-methylimidazolium chloride (EmimCl), and 1-butyl-3-methylimidazolium chloride (BmimCl), used as solvents for dissolution of the cellulose, were purchased from Chengjie Chemistry Corporation.

\subsection{Preparation of Regenerated Cellulose Films. In a typical} procedure for preparation of regenerated cellulose film, $5 \mathrm{~g}$ cotton linter sample was dispersed in $100 \mathrm{~g}$ ILs of EmimAc, $\mathrm{AmimCl}$, EmimCl, and $\mathrm{BmimCl}$, respectively. The mixture was heated at different temperatures in the range of $80^{\circ} \mathrm{C}-$ $120^{\circ} \mathrm{C}$ under magnetic stirring until cellulose dissolved in ILs completely. After dissolution, the resulting transparent solution was cast on a glass plate and then immediately coagulated in the water to obtain transparent regenerated cellulose gel. The regenerated cellulose gel was washed with running distilled water and then air dried. All films were kept in a conditioning cabinet at $50 \%$ relative humidity (RH) and $25^{\circ} \mathrm{C}$ to ensure the stabilization of their water content before characterization.
2.3. Thickness Measurements. A micrometer (Lorentzen \& Wettre, precision $1 \mu \mathrm{m}$ ) was used to measure film thickness. Measurement was taken at six different locations on each film, and the mean value was used in the calculations of the mechanical test.

2.4. Scanning Electron Microscopy Analysis. Scanning electron micrographs (SEM) were taken on a HITACHI S-3400N scanning electron microscope with $10 \mathrm{kV}$ acceleration voltage and at a magnification of 2000. The free surface and the fracture surface of the films were sputtered with gold-palladium on a HITACHI E-1010 and then observed and photographed.

2.5. Atomic Force Microscopy Analysis. Atomic force microscopy (AFM) (SPM-9600, Shimadzu) was used to study the morphology of film surface. In AFM scanning, two to four interest locations on each sample were tested. Small pieces of films were glued onto metal disks and attached to a magnetic sample holder located on the top of the scanner tube. Phase images were recorded under ambient air conditions. All of the images were recorded in contact mode using silicon cantilevers.

2.6. X-Ray Diffraction. Crystallinity of the regenerated cellulose film samples was determined by X-ray diffraction patterns using XRD-6000 instrument (Shimidzu, Japan). The method was the same as that at literature [13].

2.7. Thermal Analysis. Thermal analysis was determined by using thermogravimetric analysis (TGA) and differential thermal analysis (DTA) on a simultaneous thermal analyzer (SDT Q600 TGA/DSC, TA Instrument). The samples weighed around $10 \mathrm{mg}$ were heated from room temperature to $600^{\circ} \mathrm{C}$ at a heating rate of $10^{\circ} \mathrm{C} / \mathrm{min}$ under an inert atmosphere of $\mathrm{N}_{2}$.

2.8. Fourier Transform Infrared Spectra Analysis. Infrared spectra of cellulose film samples were recorded with a Fourier transform IR spectrometer (FT-IR TENSOR27, Germany) in ATR mode. The specimens were measured directly with a scan range from $400 \mathrm{~cm}^{-1}$ to $4000 \mathrm{~cm}^{-1}$.

2.9. CP/MAS ${ }^{13} \mathrm{C} \quad \mathrm{NMR}$ Spectra. Solid-state crosspolarization/magic angle spinning (CP/MAS) ${ }^{13} \mathrm{C}$ NMR spectra of the regenerated cellulose film samples were recorded on a Bruker AV-III $400 \mathrm{M}$ spectrometer (Germany) operated at a ${ }^{13} \mathrm{C}$ frequency of $100.6 \mathrm{MHz}$. A $4 \mathrm{~mm}$ zirconia $\left(\mathrm{ZrO}_{2}\right)$ rotor was used to pack cellulose films, and the measurement was performed using a CP pulse program with a $2 \mathrm{~ms}$ contact time and a $2 \mathrm{~s}$ delay between transitions. The spinning speed was set at $5 \mathrm{kHz}$ for all samples.

2.10. Contact Angle Measurements. Contact angles of the cellulose films were measured to calculate the surface free energies of the cellulose films. The measurements were performed at room temperature by the sessile drop method using 


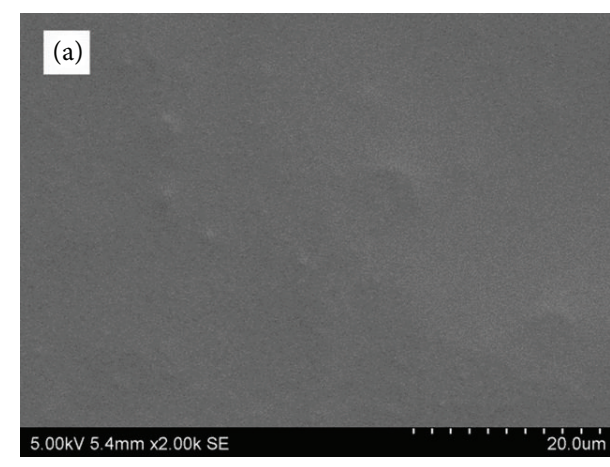

(a)

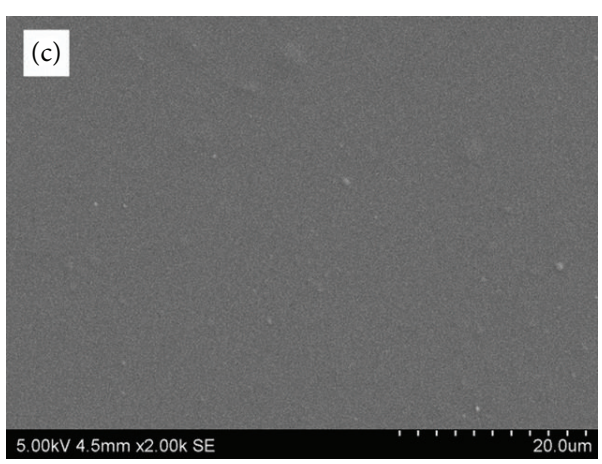

(c)

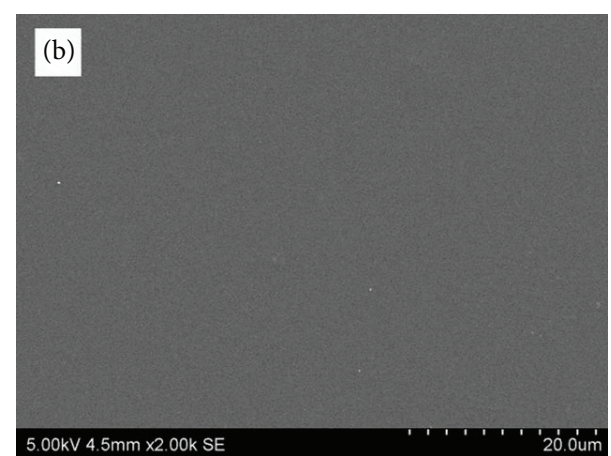

(b)

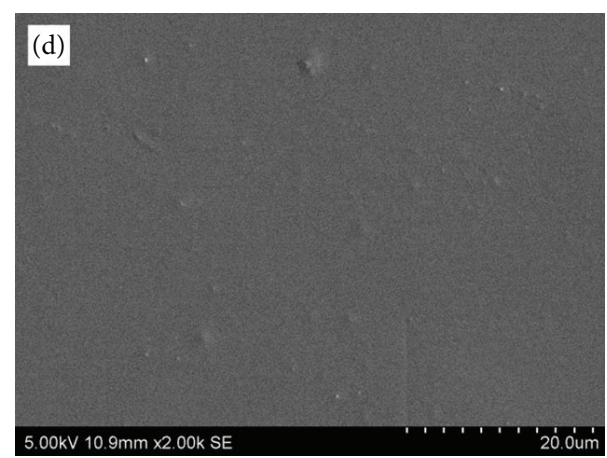

(d)

Figure 1: SEM images of regenerated films, (a) AmimCl, (b) BmimCl, (c) EmimCl, and (d) EmimAc.

TABLE 1: Crystallinity, peak positions in X-ray diffractograms, and contact angle of cellulose films.

\begin{tabular}{|c|c|c|c|c|c|c|}
\hline \multirow{2}{*}{ Sample } & \multirow{2}{*}{ Crystallinity (\%) } & \multicolumn{4}{|c|}{ Diffraction angle $2 \theta$} & \multirow{2}{*}{ Contact angle $/ \theta^{\circ}$} \\
\hline & & $(-110)$ & (110) & $(200)$ & $(020)$ & \\
\hline Cotton linter & 54.01 & 15.0 & 16.4 & 22.6 & - & - \\
\hline AmimCl & 38.41 & 12.8 & 20.2 & - & 21.2 & 38.48 \\
\hline $\mathrm{BmimCl}$ & 39.25 & 12.6 & 20.2 & - & 21.2 & 40.08 \\
\hline EmimCl & 39.24 & 12.8 & 20.6 & - & 21.2 & 54.12 \\
\hline EmimAc & 34.04 & 12.8 & 20.2 & - & 21.2 & 34.18 \\
\hline
\end{tabular}

a goniometer equipped with a high-speed camera (OCA 20, Data physics Ltd., Germany).

2.11. Tensile Strength Testing. The tensile strength of the regenerated cellulose films was measured by using a tensile testing machine (Zwick Universal testing machine Z005) at a speed of $5 \mathrm{~mm} / \mathrm{min}$. The samples were cut in the rectangular specimens with a width of $20 \mathrm{~mm}$ and length of $60 \mathrm{~mm}$, and eight replicate specimens were tested from each film type. A grip distance of $20 \mathrm{~mm}$ was maintained. The measurements were performed at $25^{\circ} \mathrm{C}$ and relative humidity of $50 \%$.

\section{Results and Discussion}

3.1. Topography of Films. The topography of produced films was analyzed by SEM and AFM. SEM and AFM micrographs of the regenerated films are shown in Figures 1 and 2. The SEM images indicated that all the regenerated films displayed smooth, highly uniform, and dense surface, indicating a complete regeneration of cellulose. The small nodules especially in the cellulose film obtained from ionic liquid EmimAc (sample d) were possibly caused by the presence of bubbles in processes of casting and coagulation. AFM images with higher resolution were recorded to determine the surface structural information of the films, whereas the height images were generated for the additional morphology and surface roughness of the films. AFM images (Figure 2) revealed that the surface of the regenerated cellulose films displayed typical granular morphology.

3.2. Crystallinity. The X-ray diffraction patterns of cotton linter and cellulose films regenerated from $\mathrm{AmimCl}, \mathrm{BmimCl}$, EmimCl, and EmimAc are shown in Figure 3. The value of crystallinity and diffraction planes of cellulose films are presented in Table 1. It was shown that the XRD profiles of cotton linter exhibited typical diffraction cellulose I angles 


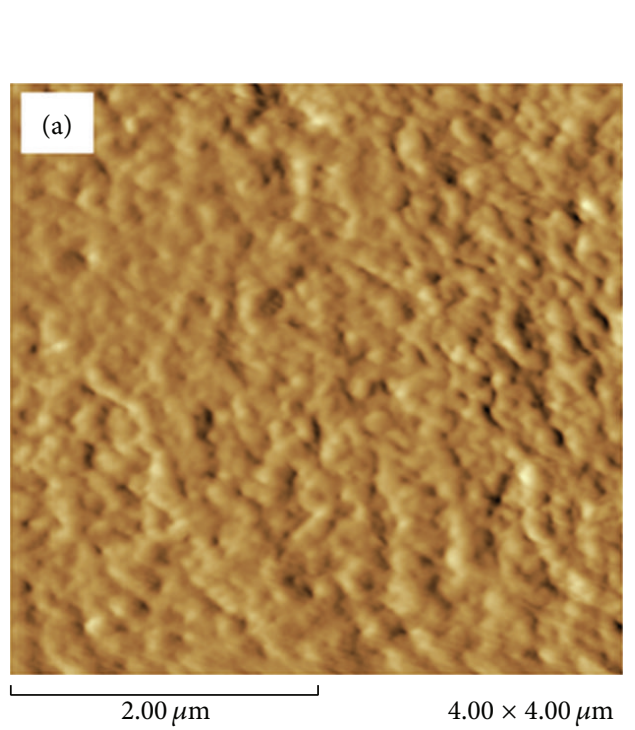

(a)

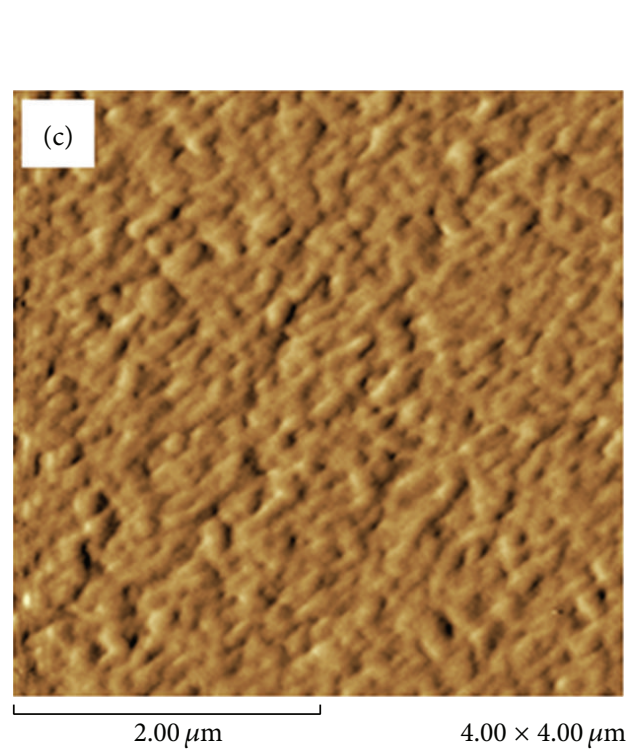

(c)

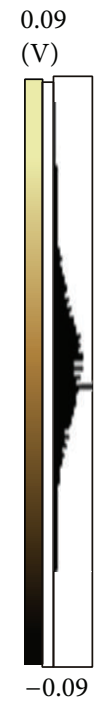

0.02

(V)
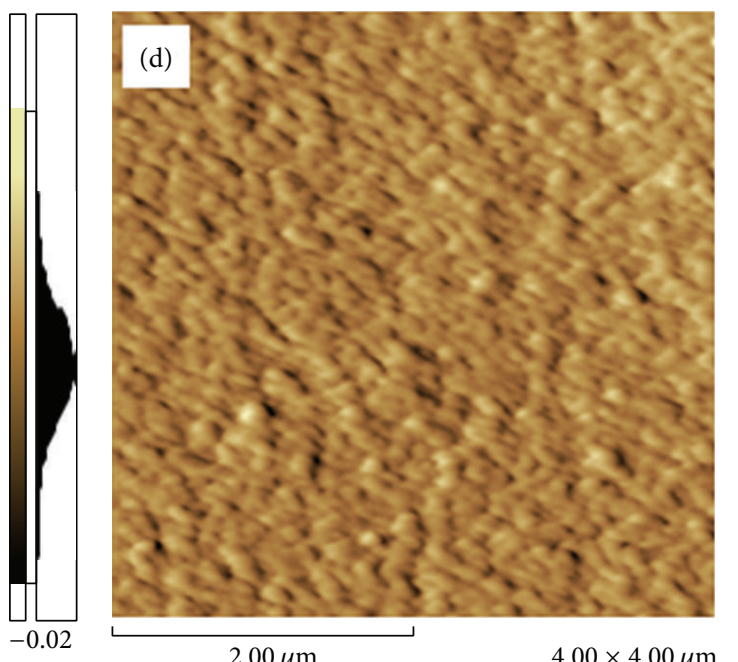

(d)

0.07

(V)

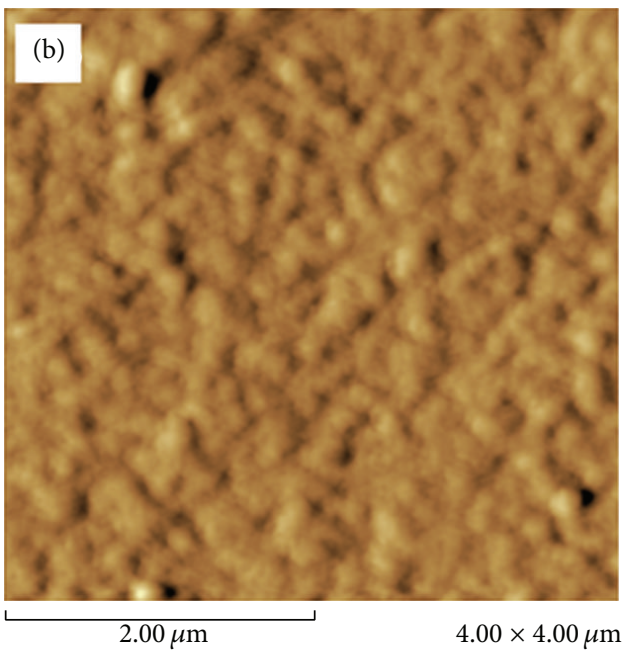

(b)

0.07

(V)

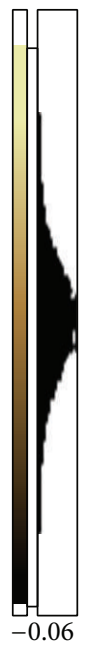

Figure 2: AFM images of regenerated films, (a) AmimCl, (b) BmimCl, (c) EmimCl, and (d) EmimAc.

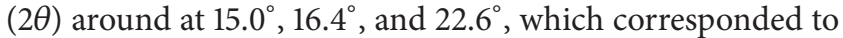
the diffraction planes of $(-110),(110)$, and (200), respectively [18]. The diffraction patterns of the regenerated films (spectra b, c, d, and e) from the four ILs showed a broad peak at $2 \theta=$ $20.2^{\circ}(110), 21.2^{\circ}(020)$ and a small broad peak at $2 \theta=12.8^{\circ}$ $(-110)$, which correspond to the crystalline form of cellulose II [19-21]. These results indicate that the transformation from cellulose I to cellulose II occurred after the dissolution and regeneration process in ILs. Compared to the original cellulose, the crystallinity of the regenerated cellulose films was lower than that of the cotton linter (Table 1). These results meant that the inter- and intramolecular hydrogen bonds between cellulose molecule were rapidly broken during the dissolution process, thus destroying the original crystalline form $[22,23]$. Moreover, the coagulation process was unfavorable to the cellulose crystallization [24]. In addition, it was noteworthy that the regenerated film fabricated with EmimAc had relatively higher hydrophilicity as the contact angle was the lowest $\left(34.18^{\circ}\right)$ as well as crystallinity (34.04\%), which demonstrated that EmimAc exhibited much stronger dissolubility for cellulose as compared with other ILs.

3.3. FT-IR. FT-IR spectroscopy was used to obtain direct information on chemical changes in cellulose during dissolution and regeneration. Figure 4 illustrates the FT-IR spectra of the regenerated films prepared from AmimCl (spectrum a), BmimCl (spectrum b), EmimCl (spectrum c), and Emi$\mathrm{mAc}$ (spectrum d). The peak at $3331 \mathrm{~cm}^{-1}$ is originated from 


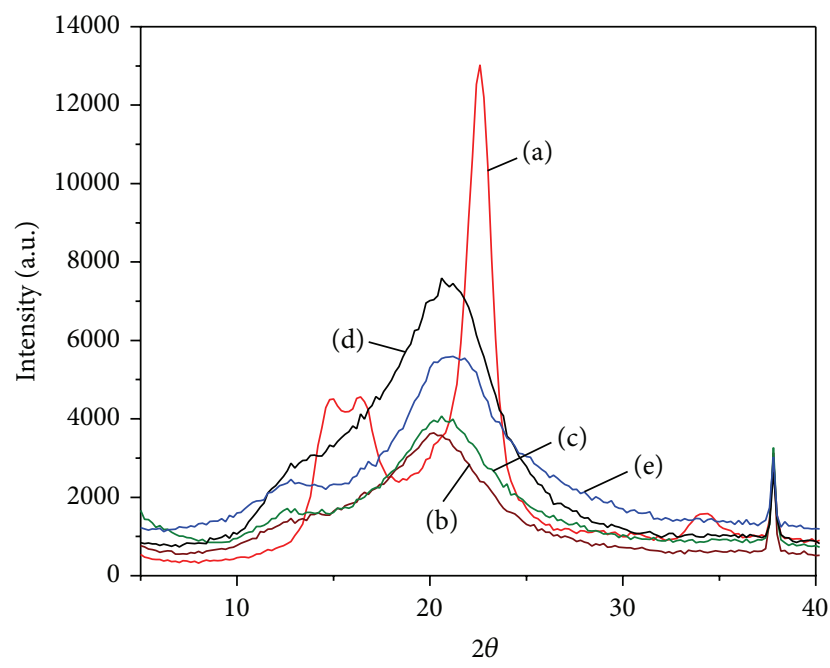

FIgURE 3: XRD images of films, (a) cotton linter, (b) AmimCl, (c) BmimICl, (d) EmimCl, and (e) EmimAc.

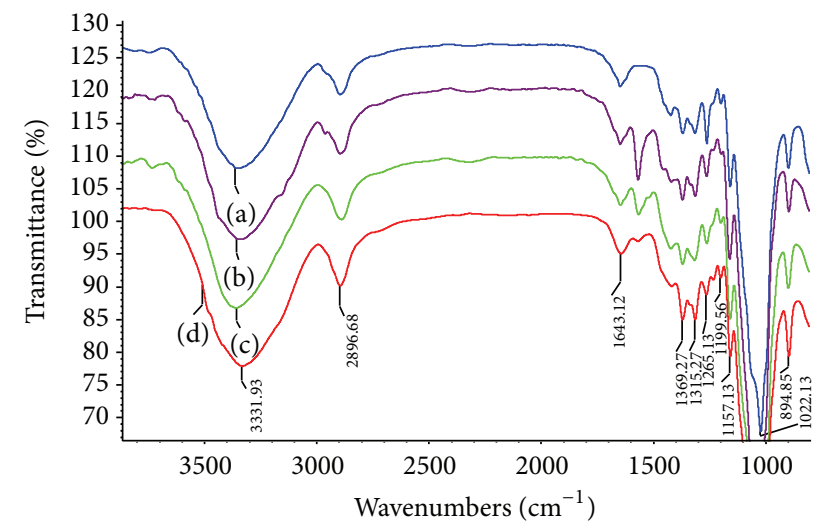

FIGURE 4: FT-IR images of films, (a) AmimCl, (b) BmimCl, (c) EmimCl, and (d) EmimAc.

the stretching of $-\mathrm{OH}$ groups and the signal at $2896 \mathrm{~cm}^{-1}$ is assigned to $\mathrm{CH}$ - stretching [25]. The band at $1643 \mathrm{~cm}^{-1}$ could be due to water in the amorphous region [26]. The peak at $1369 \mathrm{~cm}^{-1}$ is attributed to the $\mathrm{O}-\mathrm{H}$ bending vibration and the strong band at $1022 \mathrm{~cm}^{-1}$ is attributed to the characteristic C$\mathrm{O}-\mathrm{C}$ stretching. The band at $1430 \mathrm{~cm}^{-1}$ in all spectra indicated that all samples contained a mixture of crystallized cellulose II and amorphous cellulose [27]. The bands due to $\mathrm{C}-\mathrm{O}$ antisymmetric bridge stretching and $\mathrm{C}-\mathrm{O}-\mathrm{C}$ pyranose ring skeletal vibration were detected at $1157 \mathrm{~cm}^{-1}$. A small sharp band at $894 \mathrm{~cm}^{-1}$ corresponds to the glycosidic $\mathrm{C}-\mathrm{H}$ deformation with ring vibration contribution and $\mathrm{O}-\mathrm{H}$ bending, which is characteristic of $\beta$-glycosidic linkages between glucose in cellulose [28]. Moreover, the intensity of this band is relatively higher as compared with cellulose I, which corroborated the transition from cellulose I to II [29]. The bands at 1375,1315 , and $1156 \mathrm{~cm}^{-1}$ are assigned to $\mathrm{CH}$-stretching, $\mathrm{CH}_{2}$ wagging, and $\mathrm{C}-\mathrm{O}$ stretching in cellulose II, respectively [30]. Furthermore, it could be observed that these spectra were

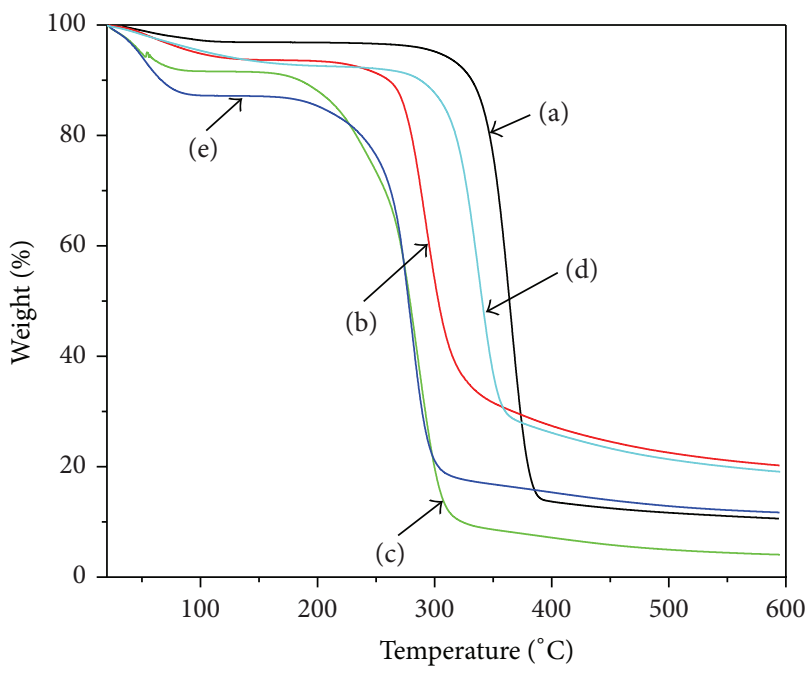

Figure 5: TGA of films, (a) virgin fibers, (b) AmimCl, (c) $\mathrm{BmimCl}$, (d) EmimCl, and (e) EmimAc.

quite similar and no new peaks appeared in the regenerated samples, which indicated that no chemical reaction between the ILs and the cellulose had occurred during the dissolution and regeneration process. In other words, $\mathrm{AmimCl}, \mathrm{BmimCl}$, EmimCl, and EmimAc were nonderivatizing solvents for cellulose, which was consistent with the literature [7,27].

3.4. Thermal Properties. Thermal degradability is affected by the chemical composition of the material. The typical TGA and DSC curves of the regenerated cellulose films are shown in Figures 5 and 6. As shown in Figure 5, the thermal decomposition of the original cellulose and the regenerated cellulose was divided into two weight loss stages, corresponding to the slow pyrolysis and fast pyrolysis stages, respectively. At the first stage, the mass loss was associated with the volatilization of water. At the fast pyrolysis stage, the onset decomposition temperatures of the regenerated cellulose films were all lower than that of the original cellulose, especially the cellulose films regenerated from $\mathrm{BmimCl}$ (sample c) and $\mathrm{EmimCl}$ (sample $\mathrm{d})$. The maximum decomposition rate $\left(T_{\max }\right.$, the decomposition temperature corresponding to the maximum weight loss rate) is shown in Figure 6. It was noted that thermal stabilities of the regenerated cellulose films were lower than that from original cellulose, which was probably caused by the lower crystallinity of regenerated cellulose as the previous work has shown that lower crystallinity and lower cellulose crystallite size can accelerate the degradation process and reduce the wood thermal stability [31].

3.5. ${ }^{13} \mathrm{C} C P / M A S$ NMR Spectra. The ${ }^{13} \mathrm{C}$ CP/MAS NMR spectra of cotton linter and different film samples are shown in Figure 7. The major signals at 105.8, 89.2, 75.3, 72.9, 71.7, and $65.4 \mathrm{ppm}$ in the spectrum of cotton linter are attributed to the C-1, C-4, C-5, C-3, C-2, and C-6, respectively, which correspond to the cellulose I structure [32]. Compared with native cellulose, the C-6 signal of the regenerated cellulose film shifted from 65.4 to $62.8 \mathrm{ppm}$ as a single peak, suggesting 


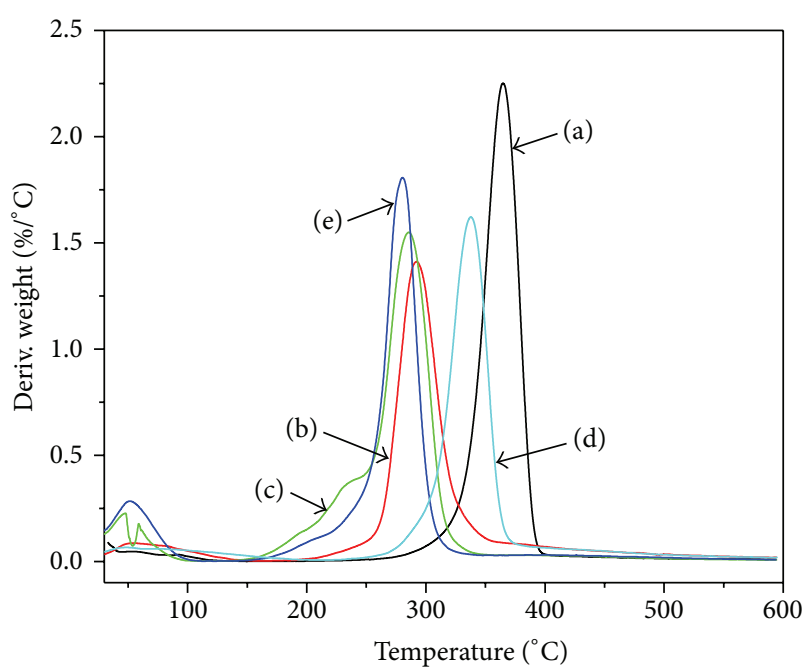

Figure 6: DSC of films, (a) virgin fibers, (b) AmimCl, (c) $\mathrm{BmimCl}$, (d) EmimCl, and (e) EmimAc.

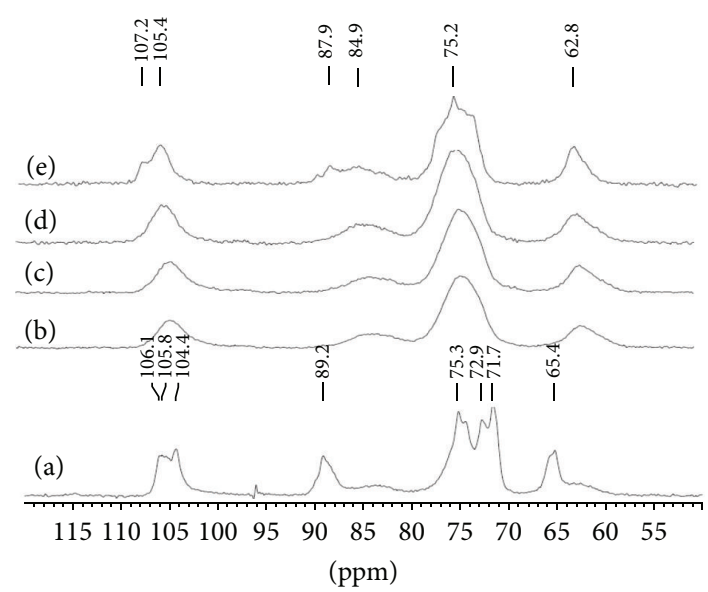

Figure 7: ${ }^{13} \mathrm{C}$ CP-MAS spectra of films, (a) virgin fibers, (b) $\mathrm{AmimCl}$, (c) BmimCl, (d) EmimCl, and (e) EmimAc.

that the "t-g" conformation (ca. $66 \mathrm{ppm}$ for C-6) of the C6-OH group for the crystalline parts of cellulose I had changed into a " $g-t$ " conformation (ca. 61-63 ppm for C-6) of cellulose II [33]. For the regenerated cellulose films, the C4 peaks located at $87.9 \mathrm{ppm}$ shifted to higher magnetic field than the native cellulose $(89.2 \mathrm{ppm})$, and the intensity was significantly lower, which suggested the dramatic decrease in the crystallinity due to the dissolution and regeneration process.

3.6. Mechanical Properties. To examine the suitability of the cellulose films for industry applications, the mechanical properties of the regenerated cellulose films were determined. The typical stress-strain curves of regenerated films prepared in AmimCl (a), BmimCl (b), EmimCl (c), and EmimAc (d) are shown in Figure 8. It can be seen from Figure 8 that the cellulose film regenerated from EmimCl caused the most excellent tensile strength, which was suggested by the highest

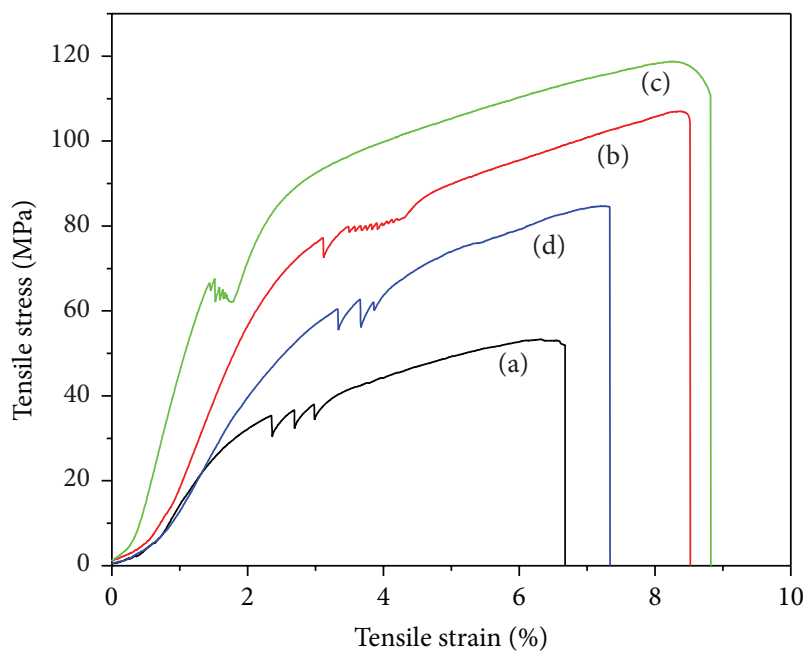

FIgure 8: Strength of films, (a) AmimCl, (b) BmimCl, (c) EmimCl, and (d) EmimAc.

tensile stress (119 Mpa). Moreover, it was noted that the tensile strain of regenerated film prepared by EmimCl was the highest (8.8\%). In addition, all the samples showed thermoplastic like behavior with stress increasing rapidly at small strains and more slowly after a yield point. In comparison, although the tensile strength value for the regenerated cellulose films obtained from AmimCl was lowest, it was still slightly higher than those of the largely used commercial polyolefin films, such as polyethylene (PE) and polypropylene (PP) with tensile strength in the range of $20-40 \mathrm{Mpa}$ [34]. Therefore, these results indicated that the environmentally friendly regenerated cellulose films had the potential to replace both nonbiodegradable PE and PP for packaging and agricultural purpose.

\section{Conclusion}

The regenerated cellulose films were successfully prepared using different ionic liquids including $\mathrm{AmimCl}, \mathrm{BmimCl}$, EmimCl, and EmimAc as solvents. It was shown that the regenerated cellulose films displayed smooth, highly uniform, and dense morphology properties. ${ }^{13} \mathrm{C} \mathrm{CP} / \mathrm{MAS} \mathrm{NMR}$ spectra and XRD corroborated that the transition from cellulose I to II had occurred after preparation. In comparison, the ionic liquid EmimAc possessed much stronger dissolubility for cellulose and the cellulose film regenerated from ionic liquid EmimCl exhibited the most excellent tensile strength. The notable properties of the regenerated cellulose films are promising for applications in transparent, biodegradable packaging and agricultural purpose as a substitute for PP and PE.

\section{Conflict of Interests}

The authors declare that there is no conflict of interests regarding the publication of this paper. 


\section{Acknowledgments}

The authors are grateful for the financial support of this research from the Beijing Higher Education Young Elite Teacher Project (YETP0766), Program for New Century Excellent Talents in University (NCET-12-0782), Natural Science Foundation of China (no. 31170557), Major State Basic Research Projects of China (973-2010CB732203), and China Ministry of Education (no. 111).

\section{References}

[1] R. A. Gross and B. Kalra, "Biodegradable polymers for the environment," Science, vol. 297, no. 5582, pp. 803-807, 2002.

[2] L. Zhang, D. Ruan, and J. Zhou, "Structure and properties of regenerated cellulose films prepared from cotton linters in $\mathrm{NaOH} /$ urea aqueous solution," Industrial and Engineering Chemistry Research, vol. 40, no. 25, pp. 5923-5928, 2001.

[3] J. Schurz, "Trends in polymer science. A bright future for cellulose," Progress in Polymer Science, vol. 24, no. 4, pp. 481-483, 1999.

[4] K. Bredereck and F. Hermanutz, "Man-made cellulosics," Review of Progress in Coloration and Related Topics, vol. 35, pp. 59-75, 2005.

[5] S. Mahmoudian, M. U. Wahit, A. F. Ismail, and A. A. Yussuf, "Preparation of regenerated cellulose/montmorillonite nanocomposite films via ionic liquids," Carbohydrate Polymers, vol. 88, no. 4, pp. 1251-1257, 2012.

[6] R. Li, L. Zhang, and M. Xu, "Novel regenerated cellulose films prepared by coagulating with water: structure and properties," Carbohydrate Polymers, vol. 87, no. 1, pp. 95-100, 2012.

[7] Y. Cao, H. Li, Y. Zhang, J. Zhang, and J. He, "Structure and properties of novel regenerated cellulose films prepared from cornhusk cellulose in room temperature ionic liquids," Journal of Applied Polymer Science, vol. 116, no. 1, pp. 547-554, 2010.

[8] S. L. Williamson, R. S. Armentrout, R. S. Porter, and C. L. McCormick, "Microstructural examination of semiinterpenetrating networks of poly(N,N-dimethylacrylamide) with cellulose or chitin synthesized in lithium chloride/, $\mathrm{N}-$ dimethylacetamide," Macromolecules, vol. 31, no. 23, pp. 81348141, 1998.

[9] J.-F. Masson and R. S. J. Manley, "Cellulose/poly(4-vinylpyridine) blends," Macromolecules, vol. 24, no. 22, pp. 59145921, 1991.

[10] T. Heinze and T. Liebert, "Unconventional methods in cellulose functionalization," Progress in Polymer Science, vol. 26, no. 9, pp. 1689-1762, 2001.

[11] K. Saalwächter and W. Burchard, "Cellulose in new metalcomplexing solvents. 2. Semidilute behavior in Cd-tren," Macromolecules, vol. 34, no. 16, pp. 5587-5598, 2001.

[12] Z. Liu, H. Wang, Z. Li et al., "Characterization of the regenerated cellulose films in ionic liquids and rheological properties of the solutions," Materials Chemistry and Physics, vol. 128, no. 1-2, pp. 220-227, 2011.

[13] H. S. Qi, C. Y. Chang, and L. N. Zhang, "Preparation of chitin/ cellulose composite gels and films with ionic liquids," Greem Chemistry, vol. 11, pp. 177-184, 2009.

[14] J. Cai and L. Zhang, "Rapid dissolution of cellulose in LiOH/ urea and $\mathrm{NaOH} /$ urea aqueous solutions," Macromolecular Bioscience, vol. 5, no. 6, pp. 539-548, 2005.
[15] R. D. Rogers and K. R. Seddon, "Ionic liquids-solvents of the future?" Science, vol. 302, no. 5646, pp. 792-793, 2003.

[16] S. Shang, L. Zhu, and J. Fan, "Physical properties of silk fibroin/cellulose blend films regenerated from the hydrophilic ionic liquid," Carbohydrate Polymers, vol. 86, no. 2, pp. 462-468, 2011.

[17] M. Gericke, P. Fardim, and T. Heinze, "Ionic liquids—promising but challenging solvents for homogeneous derivatization of cellulose," Molecules, vol. 17, no. 6, pp. 7458-7502, 2012.

[18] A. Isogai, M. Usuda, T. Kato, T. Uryu, and R. H. Atalla, "Solid-state CP/MAS 13C NMR study of cellulose polymorphs," Macromolecules, vol. 22, no. 7, pp. 3168-3172, 1989.

[19] D. Han and L. Yan, "Preparation of all-cellulose composite by selective dissolving of cellulose surface in PEG/NaOH aqueous solution," Carbohydrate Polymers, vol. 79, no. 3, pp. 614-619, 2010.

[20] H. Qi, J. Cai, L. Zhang, and S. Kuga, "Properties of films composed of cellulose nanowhiskers and a cellulose matrix regenerated from alkali/urea solution," Biomacromolecules, vol. 10, no. 6, pp. 1597-1602, 2009.

[21] S. S. Rahatekar, A. Rasheed, R. Jain et al., "Solution spinning of cellulose carbon nanotube composites using room temperature ionic liquids," Polymer, vol. 50, no. 19, pp. 4577-4583, 2009.

[22] H.-Z. Chen, N. Wang, and L.-Y. Liu, "Regenerated cellulose membrane prepared with ionic liquid 1-butyl-3-methylimidazolium chloride as solvent using wheat straw," Journal of Chemical Technology and Biotechnology, vol. 87, no. 12, pp. 16341640, 2012.

[23] S. H. Zeronian and H.-S. Ryu, "Properties of cotton fibers containing the cellulose IV crystal structure," Journal of Applied Polymer Science, vol. 33, no. 7, pp. 2587-2604, 1987.

[24] H. Zhang, J. Wu, J. Zhang, and J. He, "1-allyl-3-methylimidazolium chloride room temperature ionic liquid: a new and powerful nonderivatizing solvent for cellulose," Macromolecules, vol. 38, no. 20, pp. 8272-8277, 2005.

[25] H. Lateef, S. Grimes, P. Kewcharoenwong, and B. Feinberg, "Separation and recovery of cellulose and lignin using ionic liquids: a process for recovery from paper-based waste," Journal of Chemical Technology and Biotechnology, vol. 84, no. 12, pp. 1818-1827, 2009.

[26] J. Yin, K. Luo, X. Chen, and V. V. Khutoryanskiy, "Miscibility studies of the blends of chitosan with some cellulose ethers," Carbohydrate Polymers, vol. 63, no. 2, pp. 238-244, 2006.

[27] M. L. Nelson and R. T. O'Connor, "Relation of certain infrared bands to cellulose crystallinity and crystal lattice type, Part II. A new infrared ratio for estimation of crystallinity in celluloses I and II," Journal of Applied Polymer Science, vol. 8, no. 8, pp. 1325-1341, 1964.

[28] A. X. Jin, J. L. Ren, F. Peng et al., "Comparative characterization of degraded and non-degradative hemicelluloses from barley straw and maize stems: composition, structure, and thermal properties," Carbohydrate Polymers, vol. 78, no. 3, pp. 609-619, 2009.

[29] F. Carrillo, X. Colom, J. J. Suñol, and J. Saurina, "Structural FTIR analysis and thermal characterisation of lyocell and viscosetype fibres," European Polymer Journal, vol. 40, no. 9, pp. 22292234, 2004.

[30] J. Široký, R. S. Blackburn, T. Bechtold, J. Taylor, and P. White, "Attenuated total reflectance Fourier-transform Infrared spectroscopy analysis of crystallinity changes in lyocell following continuous treatment with sodium hydroxide," Cellulose, vol. 17, no. 1, pp. 103-115, 2010. 
[31] M. Poletto, A. J. Zattera, M. M. C. Forte, and R. M. C. Santana, "Thermal decomposition of wood: influence of wood components and cellulose crystallite size," Bioresource Technology, vol. 109, pp. 148-153, 2012.

[32] V. Castelvetro, M. Geppi, S. Giaiacopi, and G. Mollica, "Cotton fibers encapsulated with homo- and block copolymers: synthesis by the atom transfer radical polymerization grafting-from technique and solid-state NMR dynamic investigations," Biomacromolecules, vol. 8, no. 2, pp. 498-508, 2007.

[33] K. Kamide, K. Okajima, and K. Kowsaka, "Dissolution of natural cellulose into aqueous alkali solution: role of supermolecular structure of cellulose," Polymer Journal, vol. 24, no. 1, pp. 71-86, 1992.

[34] H. Ding, Handbook of Plastic Industry, Chemical Industry Press, Beijing, China, 1995. 

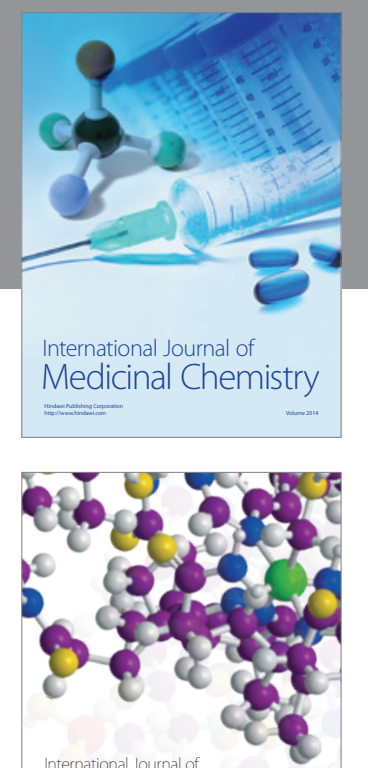

\section{Carbohydrate} Chemistry

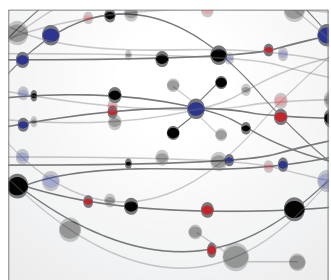

The Scientific World Journal
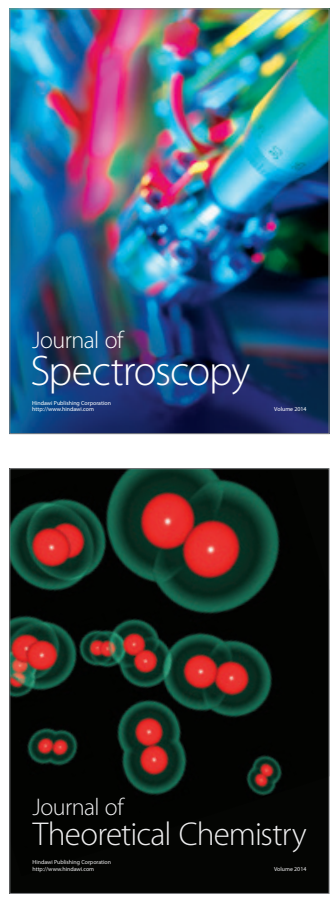
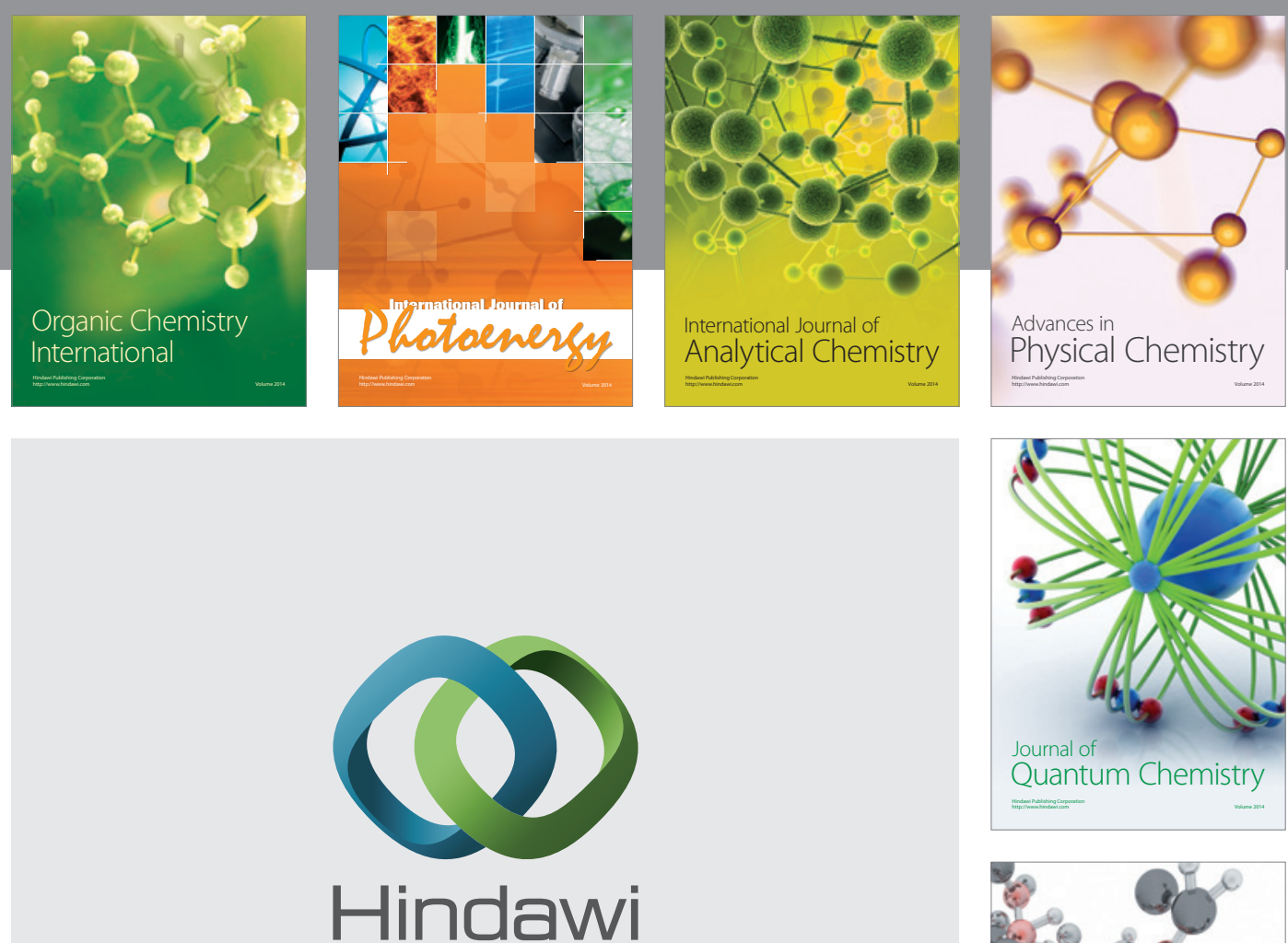

Submit your manuscripts at

http://www.hindawi.com

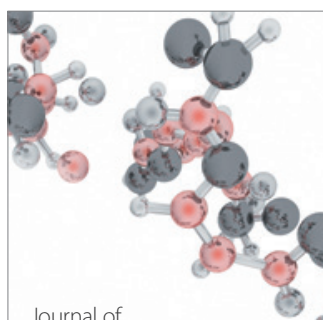

Analytical Methods

in Chemistry

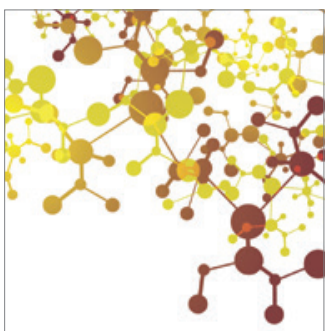

Journal of

Applied Chemistry

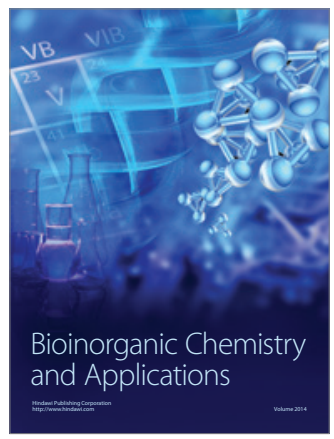

Inorganic Chemistry
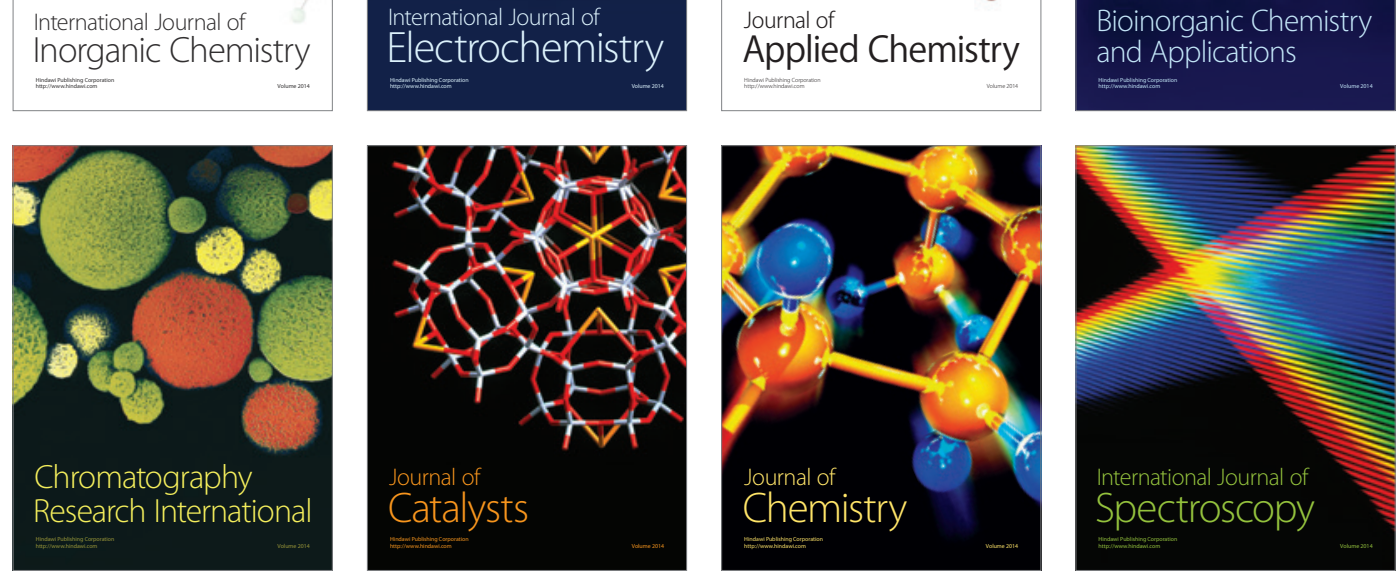